\title{
Perturbações do desenvolvimento infantil - conceitos gerais
}

Paula Pires de Matos*

\section{RESUMO}

O desenvolvimento psico-motor humano é consequência da evolução e encefalização da espécie e tem características únicas que são detalhadas neste artigo. Referem-se os factores de risco genéticos e do ambiente na modulação do neurodesenvolvimento e a sua relevância para a determinação do fenotipo desenvolvimental e comportamental. Define-se normalidade quantitativa e qualitativa em desenvolvimento psico-motor numa perspectiva dimensional e explicitam-se as sequências do desenvolvimento nas suas várias áreas. Abordam-se os conceitos chave nas principais perturbações do desenvolvimento infantil.

Palavras-chave: Perturbações do Desenvolvimento; Factores de Risco; Critérios de Diagnóstico.

\section{ESPECIFICIDADES DO DESENVOLVIMENTO} HUMANO

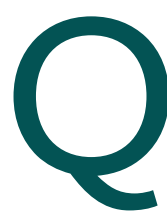

uando se fala em desenvolvimento psicomotor e perturbações do desenvolvimento infantil temos que inserir os conceitos na especificidade própria da nossa espécie, tão diferente do resto dos primatas.

Fazendo parte do grupo dos grandes mamíferos e dos primatas, temos gestações prolongadas, habitualmente de um único feto, raramente de dois ou mais fetos. No entanto, ao contrário dos outros primatas, que mal nascem têm a capacidade de procurar a mama da mãe e agarrar-se ao corpo dela para fugir dos predadores, as nossas crias nascem neurológica e fisicamente imaturas, totalmente dependentes da mãe para a alimentação, termo-regulação, protecção e sobrevivência. Nascemos, assim, tão indefesos como as crias dos pequenos mamíferos, como os coelhos ou ratos.

E esta imaturidade neurológica ao nascer, numa espécie que, sendo parte dos primatas, deveria ter crias maduras, deve-se ao processo de encefalização da espécie homo sapiens sapiens. Na evolução da espécie, a encefalização levou a um pregueamento do córtex cerebral para que coubesse na caixa craniana, a um alar-

*Pediatra, Centro de Desenvolvimento Infantil Diferenças - APPT21 Clínica Médica Gerações gamento da pélvis das fêmeas da espécie para dar passagem a uma cabeça fetal maior e à permeabilidade das suturas cranianas que permite o seu cavalgamento na passagem pelo canal de parto. Mas, mesmo assim, todas estas estratégias não foram suficientes e houve necessidade de antecipar o trabalho de parto, nascendo as crias quase no limite da sua viabilidade. ${ }^{1}$

Ao contrário dos outros grandes primatas, o desenvolvimento do nosso sistema nervoso central não está completo na altura do nascimento mas ainda se prolonga ao longo do primeiro ano de vida. Assim, a cria da nossa espécie terá 9 meses de gestação intra-uterina e 12 meses de "gestação extra-uterina», sendo este tempo de uma enorme importância no desenvolvimento do indivíduo e também um factor de plasticidade e vulnerabilidade acrescidas.

O recém-nascido da espécie humana é extraordinariamente incompetente para a sua sobrevivência ao nascer, tendo apenas movimentos voluntários oculares e da boca, orientados pelo estímulo visual e táctil para a fonte de alimento. Todos os outros movimentos como a preensão palmar, o reflexo de Moro, os movimentos dos membros, a marcha automática, são reflexos.

As implicações desta imaturidade neurológica e desta dependência são de ordem física (alimentação, higiene, termo-regulação), desenvolvimental e emocional. Assim, torna-se óbvio que o recém-nascido humano 
necessite de um contacto constante com a sua progenitora que promoverá os cuidados alimentares, a termo-regulação, a protecção física, ajudará a regular os estadios emocionais e terá com ele uma interacção conducente a um neurodesenvolvimento harmonioso. Convém também recordar que, embora na sociedade ocidental haja hábitos que tendem a separar precocemente as crias das mães, a observação das culturas ditas primitivas, ensina-nos bastante sobre o instinto natural do cuidado infantil: os bebés andam agarrados/enfaixados ao corpo das mães no primeiro ano de vida e curiosamente não há registo de cólicas, regurgitação, problemas de sono e choros excessivos.

A forma como cada civilização trata os seus recém-nascidos é dependente dos hábitos transmitidos de mães para filhas, de conceitos adquiridos em cada cultura e das crenças sobre educação e cuidados infantis.

\section{FACTORES DE RISCO EM NEURODESENVOLVIMENTO - GENÉTICA E AMBIENTE}

O desenvolvimento psico-motor depende da inter-relação entre os factores próprios do indivíduo (genéticos) e os factores do ambiente. Este desenvolvimento tem uma predeterminação filogenética, ou seja, existem competências, habilidades, que todos os indivíduos de uma mesma espécie desenvolvem. No nosso caso específico existe uma evolução previsível nas várias áreas do desenvolvimento. Assim, todos os indivíduos neurológica e fisicamente íntegros aprendem a andar, a falar e a manipular objectos variados.

Apesar de um fundo genético e áreas funcionais cerebrais semelhantes, as variadas habilidades e competências têm tempos diferentes de aquisição na evolução da espécie, sendo que as habilidades motoras grosseiras e visuo-espaciais são mais antigas do que as linguísticas e cognitivas verbais.

Assim, as competências filogeneticamente mais antigas (motor grosseiro, visual) são menos atingidas nas perturbações do desenvolvimento, mas a capacidade específica da espécie, a linguagem, é aquela que é atingida na maioria das perturbações do desenvolvimento, mesmo nas mais ligeiras. Apenas as lesões mais generalizadas e graves afectam significativamente a motricidade grosseira. Percebe-se também que uma motricidade grosseira mantida não é uma garantia de desenvolvimento normal mas que uma linguagem com evolução alterada é quase invariavelmente um sinal de perturbação do desenvolvimento.

As perturbações ligeiras e frequentes do desenvolvimento são aquelas que se caracterizam por incapacidades menos relevantes para a sobrevivência da espécie, sendo contudo importantes para a «sobrevivência» individual na sociedade instruída e instrumentalizada que criámos. Uma perturbação fonológica ligeira apenas se torna um problema na sociedade leitora moderna, a dislexia só surge como perturbação do desenvolvimento nos últimos 5000 anos da nossa espécie, altura em que se inventou a escrita.

O desenvolvimento do indivíduo também depende de factores genéticos individuais herdados dos progenitores. As alterações genéticas são um dos principais factores de risco das perturbações do desenvolvimento infantil. A manifestação clínica (fenotipo desenvolvimental e comportamental) de alterações genéticas e cromossómicas depende da inter-relação desses genes alterados com os outros genes do indivíduo e a sua expressão é determinada pela modulação feita pelo ambiente, tanto intra-uterino como extra-uterino. Esta modulação é provavelmente mais importante na fase de maior crescimento do sistema nervoso central, ou seja, nos 9 meses de gestação e nos primeiros 12 meses de vida. Daí que, em qualquer indivíduo que apresente factores de risco conhecidos para o desenvolvimento, seja extraordinariamente importante a intervenção precoce. Esta vai actuar na fase de maior plasticidade e maior capacidade de modificação de circuitos neuronais, melhorando as competências do indivíduo. Sabe-se que o córtex neonatal não é nem localizado nem muito especializado na altura do nascimento. Este facto permite que a interacção com o ambiente tenha um papel crucial na expressão dos genes e no fenotipo cognitivo final. Surpreendentemente, muito pouco é estritamente predeterminado ou fixado permanentemente. Assim, a epigénese é probabilística, e a expressão genética é dependente da actividade. ${ }^{2} \mathrm{~A}$ epigénese corresponde à variabilidade na expressão dos genes induzida pelas experiências vividas pelo indivíduo durante o seu desenvolvimento, mas que não implica modificações nas sequências de ADN. A existência destas experiências é introduzida pelo acaso, ou seja, pelo ambiente em que nos desenvolvemos. Exceptua-se a intervenção precoce, que pretende exactamente fornecer ao indiví- 
duo vivências sensoriais, motoras e cognitivas para que a expressão genética seja voluntariamente melhor do que seria pela simples casualidade. Assim percebe-se que a expressão genética, para além de depender da probabilidade de acontecerem ou não determinados estímulos ou experiências, é dependente desta mesma actividade e/ou experiência.

Os factores de risco do ambiente podem dividir-se em intra-uterinos (congénitos), perinatais e extra-uterinos. A desnutrição, hipoxia e noxas (tóxicos, álcool, drogas, metais pesados, medicamentos, infecções congénitas e lesões acidentais) encontram-se descritos como factores de risco intra-uterinos, enquanto os acidentes periparto com anóxia ou hipóxia são considerados factores de risco perinatais. Os factores de risco extra - uterinos incluem: as infecções, os traumatismos, a hipóxia, os tóxicos e as alterações graves da vinculação com maus tratos, abusos e negligência.

\section{NOÇÃO DE NORMALIDADE EM DESENVOLVIMENTO PSICO-MOTOR}

Um desenvolvimento psico-motor (DPM) normal define-se pelos limites de idade em que se fazem as várias aquisições e pela adequação qualitativa dessas aquisições. Define-se também pela adequação funcional e adaptativa, para cada idade, das competências adquiridas.

A definição de normal e «anormal» em desenvolvimento não é categórica. Ou seja, não há um limite ou fronteira bem definidos da idade normal de aquisição das várias competências. A definição de normalidade é, sobretudo, uma noção dimensional (uma curva ou linha de distribuição contínua), em que o limiar da normalidade está ao lado do limiar da «anormalidade». Pensa-se que, tal e qual como na distribuição das estaturas de uma população, na aquisição de qualquer competência existe uma distribuição gaussiana das idades em que a aquisição é feita, sendo que a definição de normalidade é quase arbitrariamente definida quando não se ultrapassam os dois desvios padrão. Tome-se como exemplo a aquisição da marcha, definida como normal entre os 9 e 18 meses. Esta definição está baseada em observações nas quais se verifica que a aquisição da marcha depois dos 18 meses está normalmente associada a outras alterações do desenvolvimento e que uma percentagem elevada destes indivíduos apresen- ta no seguimento alterações no desenvolvimento psico-motor. Em contrapartida, aqueles que adquirem a marcha até aos 18 meses têm uma maior probabilidade de não ter perturbação do desenvolvimento. Assim, e por estudos estatísticos de observações populacionais, temos uma noção razoavelmente precisa da normalidade e da variação da normalidade em que se fazem as aquisições do DPM, dos sinais de «alarme»e do que é considerado «anormal»(ou não convencional). Ou seja, há uma definição de normalidade por referência à norma. ${ }^{3}$ Convém referir também que há variações «culturais» nas idades normais das aquisições psicomotoras, uma vez que estas são dependentes da estimulação diferente consoante os hábitos de cada família ou sociedade. Um exemplo interessante é a sequência da aquisição motora grosseira de rebolar da posição de prono para supino e depois de supino para prono. Desde que foi feita a recomendação sistemática de deitar os bebés de costas para dormir, os pais deitam-nos assim em qualquer circunstância e não lhes dão a oportunidade durante os períodos de vigília de estarem de barriga para baixo a brincar. Assim, actualmente observa-se que os bebés viram-se um pouco mais tarde e começam por fazer a viragem supino-prono e só depois a de prono-supino.

No entanto, há também nuances de normalidade qualitativa em DPM. Vejamos uma vez mais o exemplo da aquisição da marcha. Uma criança pode adquiri-la dentro da idade considerada normal e, no entanto, as características da marcha serem de tal forma peculiares ou diferentes que provoquem alteração da funcionalidade, e assim temos uma alteração qualitativa do desenvolvimento. As alterações da linguagem nas perturbações do espectro do autismo altamente funcionantes são outro bom exemplo de alterações qualitativas do DPM. Nestes indivíduos a linguagem pode ser formalmente correcta e os conteúdos serem bizarros, haver incapacidade para o diálogo e comunicação. Estas alterações também afectam a funcionalidade e devem ser objecto de intervenção. ${ }^{3}$

Torna-se complicado definir normalidade naqueles indivíduos que apresentam capacidades do desenvolvimento no limiar do normal, e isto surge exactamente por não podermos definir normalidade de forma categórica mas sim de forma dimensional. Assim, a classificação de um determinado padrão de desenvolvi- 
mento em normal ou «anormal» (mais correctamente apelidado de não convencional) será feita não só pela apresentação ou ausência de uma determinada capacidade, mas sobretudo pela sua repercussão no funcionamento do indivíduo, ou mais precisamente, se essa alteração do desenvolvimento implica ou não o recurso a medidas de apoio de alguma ordem.

Para a definição de normalidade e avaliação das crianças temos que ter em conta a avaliação das várias áreas do desenvolvimento psico-motor e a avaliação das sequências de desenvolvimento. Podemos dividir grosseiramente as áreas do desenvolvimento psicomotor infantil em motricidade grosseira e fina, linguagem e cognição verbal, cognição não-verbal (visuo-perceptual), socialização, comportamento adaptativo (autonomia) e atenção. O DPM infantil faz-se invariavelmente em sequências determinadas e invariáveis - são as sequências desenvolvimentais. Na motricidade grosseira o desenvolvimento faz-se sempre numa progressão cefalo-caudal: primeiro segurar a cabeça, depois usar as mãos, os pés, sentar, deslocar-se (de qualquer forma, como gatinhar, arrastar ou rabejar), pôr-se de pé, caminhar e por fim correr. O desenvolvimento motor também se faz numa sequência de movimento geral/global para fino/particular, ou seja, de movimentos generalizados e pouco precisos, que envolvem todo o corpo, para movimentos especializados, unilaterais e finos, orientados com lateralidade e precisão e com crescente complexidade, ao longo da vida. A esta especialização dos movimentos chama-se lateralização, que tem como base neurológica a localização especializada de determinadas funções em áreas específicas do cérebro. Tome-se como exemplo a motricidade fina: aos 4 meses o bebé alcança os objectos com as duas mãos mostrando o entusiasmo com movimentos globais de todo o corpo, aos 12 meses alcança os objectos com um movimento de pinça fina de uma só mão, e aos 12 anos, com treino, consegue tocar um instrumento musical de forma profissional.

No início das aquisições cognitivas não-verbais (processos cognitivos independentes da linguagem, competências dependentes do processamento visual e espacial) a sequência de desenvolvimento não é independente das habilidades motoras finas pois, nas tarefas classicamente chamadas de coordenação olho-mão, intervêm simultaneamente dois processos desenvolvi- mentais, a coordenação motora fina e o processamento visuo-espacial. Como exemplo vejamos a tarefa de colocar um círculo no respectivo lugar de um puzzle: a criança tem que ter a capacidade motora fina de agarrar eficazmente no objecto e encaixá-lo no seu lugar. Simultaneamente tem que ter adquirido a capacidade perceptual visual de emparelhar formas iguais de modo a perceber onde vai colocar a peça. Mais adiante no DPM as tarefas cognitivas não verbais podem incluir ou não necessidades motoras finas elaboradas, sendo mais fácil a sua avaliação e apreciação separadas.

$\mathrm{Na}$ linguagem as sequências de desenvolvimento também são invariáveis, com pequenas peculiaridades interessantes. No desenvolvimento da linguagem há uma evolução desfasada no tempo da capacidade de compreensão e da capacidade de expressão linguística. Os bebés e as crianças pequenas compreendem muito mais do que aquilo que conseguem exprimir. Sabe-se que todos os bebés vocalizam da mesma forma seja qual for a língua em que são «banhados», mas, a partir dos 6 meses começam a utilizar sons específicos da sua língua. A isto chama-se a impregnação fonológica, que é a construção de um «dicionário» mental das representações fonológicas que existem na língua do indivíduo e que é feita nos primeiros anos de vida e mais dificilmente modificável à medida que a criança cresce (daí o ditado «burro velho não aprende línguas»). Por esta razão é que os chineses têm uma quase impossibilidade em dizer o "r» e os espanhóis têm dificuldade em aprender o português, pois têm menos fonemas do que nós. Assim, começamos por vocalizar apenas vogais, depois sílabas simples $\mathrm{C}-\mathrm{V}$, polissílabos, jargão, primeiras palavras, frases de 2 palavras (apenas nomes), frases com verbos, frases com partículas de ligação, reconto sequencial de acontecimentos e histórias, até ao uso da linguagem com características meta linguísticas e abstractas. Pode considerar-se a aprendizagem da leitura e escrita como a elaboração mais fina da linguagem.

A linguagem evolui paralelamente também nos seus vários componentes como a articulação/fonologia, o léxico/vocabulário, a semântica/significado, a morfo-sintaxe/gramática e a pragmática. Na articulação sabemos que inicialmente a criança comete muitos erros articulatórios, tornando-se a linguagem mais compreensível aos 3 anos e sem erros articulatórios aos 5 anos. 
No entanto, é natural a persistência de pequenos erros, como a dificuldade em articular o «r» frontal (como em cara). Na evolução do léxico a criança começa por dizer nomes concretos (nomes de pessoas e objectos) e só depois nomes abstractos (sentimentos) e acções (verbos). Na primeira fase há uma generalização do nome para conceitos de uma mesma família como por exemplo «mãe» para todas as mulheres ou «cão» para todos os animais de quatro patas, seguida da especialização e precisão do vocabulário, ou seja, há uma evolução para uma especialização semântica. As primeiras frases começam por ser de dois nomes, depois são introduzidas acções (verbos) e mais tarde as partículas de ligação. Há uma tendência para fazer a regularização dos tempos verbais dos verbos irregulares (como em «eu di», regularizado de «eu vi», em vez de dizer «eu dei»). Na evolução da pragmática, à medida que a criança evolui na socialização também passa a adequar o seu discurso e vocabulário aos interlocutores e situações específicas em que se encontra. Também podemos fazer uma apreciação quantitativa ou qualitativa das competências linguísticas.

Um dos objectivos das consultas de saúde infantil é monitorizar o DPM com a finalidade de rastrear precocemente perturbações do desenvolvimento, de modo a pôr em marcha a intervenção necessária o mais cedo possível. Esta deve ser específica para o perfil funcional do indivíduo, com o objectivo de melhorar o seu funcionamento e maximizar as suas potencialidades, tornando-o o mais autónomo possível.

Quando encontramos uma criança com uma perturbação do desenvolvimento temos vários objectivos em vista: investigar a etiologia para estabelecer o prognóstico e a evolução, fazer um perfil funcional para adequar a intervenção, desencadear o processo de intervenção e posteriormente monitorizá-lo.

\section{PERTURBAÇÕES DO DESENVOLVIMENTO INFANTIL}

As perturbações do desenvolvimento infantil estão classificadas em dois sistemas classificativos internacionais, o DSM IV - TR e o ICD 10. Estes devem ser utilizados de forma a conseguir uma comunicação eficaz inter-pares e para que se possa investigar nesta área. Não devem ser utilizadas expressões como «atraso do desenvolvimento», «atraso do desenvolvimento psico-motor $(\mathrm{ADPM}) »$ e outras denominações imprecisas.
Quando é feito o diagnóstico de uma perturbação do desenvolvimento, a sua classificação (diagnóstica) deverá ser feita em várias dimensões como a biológica, desenvolvimental, emocional e comportamental, e social. Como exemplo temos a trissomia 21: trata-se de uma doença biológica genética, com provável diagnóstico desenvolvimental de deficiência cognitiva, com ou sem uma perturbação emocional e factores protectores e de risco sociais e familiares.

As perturbações do desenvolvimento podem, grosso modo, dividir-se em perturbações «gerais» e perturbações específicas do desenvolvimento. Nas primeiras, todos os aspectos desenvolvimentais e cognitivos do indivíduo estão afectados, embora o possam estar em graus de gravidade diferentes. Nestas estão incluídas a Deficiência Mental (mais conhecida como atraso mental) e as Perturbações do Espectro do Autismo (traduzida do DSM IV como Perturbação Global do Desenvolvimento). Nas segundas estão incluídas as perturbações mais frequentes e que apenas têm comprometidas áreas específicas do desenvolvimento, estando íntegras as restantes áreas. Tratam-se das Perturbações Específicas da Linguagem, a Perturbação Cognitiva Não-Verbal, as Perturbações Específicas da Aprendizagem (Dislexia, Disgrafia/Disortografia e Discalculia), a Perturbação do Desenvolvimento da Coordenação Motora, a Perturbação de Hiperactividade com Défice de Atenção, a Perturbação de Oposição e a Perturbação de Conduta (DSM-IV).

As perturbações do desenvolvimento coexistem de forma mais frequente do que seria de esperar. Ter uma perturbação de desenvolvimento é um factor de risco acrescido para co-morbilidade com outra perturbação do desenvolvimento ou com uma perturbação emocional e comportamental.

A Deficiência Mental (DM) ou Deficiência Cognitiva (ou Atraso Mental, como era conhecido anteriormente) é definida no DSM IV por se apresentar com um défice cognitivo de dois desvios padrões abaixo da média (QI $70 \pm 5)$ acompanhado de défices, insuficiências ou incapacidades no comportamento adaptativo, nomeadamente nas áreas da comunicação, cuidados próprios, vida familiar, vida social/aptidões interpessoais, uso de recursos comunitários, auto-controlo, aptidões escolares funcionais, trabalho, ócio, saúde e segurança. 
O seu início acontece antes dos 18 anos e todas as áreas do DPM estão afectadas. É dividida por graus de gravidade consoante o QI do indivíduo em: DM ligeira (QI: 50-55 a 70); DM moderada (QI: 35-40 a 50-55); DM grave (QI: 20-25 a 35-40); DM profunda (QI <25-20). A definição de gravidade consoante o QI é útil para estudos mas menos útil para a apreciação da funcionalidade e autonomia do indivíduo, pois estas não dependem só do QI mas sobretudo do comportamento adaptativo e capacidade de socialização. Tomemos como exemplo dois indivíduos com QI semelhante mas um com Trissomia 21 e o outro com Autismo. Ninguém duvida que a capacidade de autonomia será maior para o primeiro e que a funcionalidade do segundo é sobretudo prejudicada pelas incapacidades de comunicação e socialização tornando-o dependente em maior grau do que o primeiro.

A maioria dos médicos que trabalham em Desenvolvimento também utiliza a definição da Academia Americana de Deficiência Mental (AAMR 2002) que se foca sobretudo nas capacidades adaptativas e de autonomia do indivíduo e da sua necessidade de apoio.

As etiologias da deficiência mental são muito variadas, entre genéticas e ambientais. Numa percentagem razoável de casos não se consegue estabelecer a sua etiologia.

As Perturbações do Espectro do Autismo ou Perturbações Globais do Desenvolvimento (tradução directa do DSM IV) caracterizam-se por alterações qualitativas em três áreas do desenvolvimento: perturbação na comunicação, perturbação na interacção social e padrões de comportamento, interesses e actividades repetitivos, restritos e estereotipados. Na perturbação qualitativa da comunicação haverá alterações desde a ausência de linguagem (não compensada por mímica ou gesto) até a uma linguagem formalmente correcta mas com incapacidades pragmáticas e de conversação, com idiossincrasias, alterações na imitação e jogo simbólico pobre. A perturbação da interacção social caracteriza-se pela incapacidade em estabelecer relações sociais apropriadas com os pares, incapacidade no uso da expressão facial e gestos que regulam a interacção social, incapacidade na partilha de interesses e reciprocidade social e emocional. Os padrões de comportamento, interesses e actividades repetitivos, restritos e estereotipados são anormais na intensidade e no objec- tivo. Possuem aderência inflexível a rituais ou comportamentos não funcionais, maneirismos motores repetitivos e estereotipados e por vezes persistente preocupação com partes dos objectos. A alteração qualitativa da interacção social deve-se a uma alteração da empatia ou seja, à incapacidade para perceber o outro como indivíduo com experiências e emoções diversas do próprio. Esta alteração da empatia será o núcleo fundamental de incapacidade nas Perturbações do Espectro do Autismo.

Existem variações de gravidade e apresentação clínica nestas perturbações, desde o Autismo de Kanner, típico, com todos os critérios e défice cognitivo, ao autismo atípico (designado de perturbação pervasiva do desenvolvimento sem outra especificação no DSM IV) e ao Síndrome de Asperger.

No Síndrome de Asperger temos perturbação na interacção social e padrões de comportamentos, interesses e actividades repetitivos, restritos e estereotipados, sem um atraso quantitativo da linguagem mas com alterações qualitativas que se manifestam por peculiaridades na expressão linguística, alterações na compreensão não literal da linguagem e alteração na pragmática e conversação. Estas crianças têm inteligência normal ou mesmo acima da média. É um diagnóstico feito, na maioria das vezes, já em idade escolar. Atendendo à elaboração e conhecimentos acima da média em quantidade e profundidade sobre determinados assuntos (os tais interesses restritos e exagerados no foco) são muitas vezes referenciados como crianças sobredotadas, de forma errada, pois têm défices noutras áreas e não possuem grande imaginação. ${ }^{3}$

A Perturbação de Desenvolvimento da Coordenação Motora caracteriza-se por haver um desempenho nas actividades quotidianas que requerem coordenação motora abaixo do nível esperado para a idade cronológica e quociente de inteligência do indivíduo, interferindo o défice de coordenação motora significativamente com as actividades da vida quotidiana e o rendimento escolar do indivíduo. Esta perturbação não é devida a um estado físico geral (muito importante excluir perturbação neuro-motora) e não preenche os critérios de Perturbação Global do Desenvolvimento (Perturbação do Espectro do Autismo). Trata-se assim de um diagnóstico de exclusão. ${ }^{3}$

As Perturbações Específicas da Linguagem (PEL) 
são definidas no DSM IV por um desempenho linguístico significativamente inferior ao desempenho obtido nas outras áreas do desenvolvimento psico-motor. Dividem-se em vários tipos: PEL Expressiva, PEL Mista (Receptiva-Expressiva), PEL Fonológica, Gaguez e Perturbação da Comunicação sem outra especificação. É também, um diagnóstico de exclusão. Quando uma criança apresenta um atraso na aquisição da linguagem temos que ter em conta que a principal causa do atraso de linguagem é a Deficiência Mental, seguida das Perturbações do Espectro do Autismo e só por último surgem as PEL e a deficiência auditiva. A persistência de uma PEL para além dos 5 anos de idade constitui factor de risco para Perturbação Específica da Aprendizagem. ${ }^{3}$

As Perturbações Específicas da Aprendizagem subdividem-se em perturbações da leitura, escrita, cálculo e mista. Na terminologia europeia referimo-nos a estas perturbações como Dislexia, Disgrafia/Disortografia e Discalculia. Os critérios do DSM IV referem que, para se fazer o diagnóstico destas perturbações, o desempenho nas tarefas de leitura, escrita ou cálculo deve ser significativamente inferior ao esperado para a idade, nível de escolaridade e inteligência do indivíduo, esperando que a criança tenha sido alvo de condições de ensino apropriadas e não apresente deficiência mental ou perturbações globais do desenvolvimento. ${ }^{3-5}$

A dislexia apresenta-se habitualmente como uma dificuldade inesperada na aprendizagem da leitura e escrita, numa criança sem défice cognitivo, sem sinais prévios que nos fariam esperar dificuldades, e que é exposta a um ensino adequado. É uma perturbação com base genética e tradução neurobiológica comprovadas. Caracterizada por dificuldades no reconhecimento correcto e/ou fluente das palavras, diminuição da capacidade de descodificação e dificuldade na ortografia. Estas dificuldades resultam, tipicamente de um défice no componente fonológico da linguagem que é muitas vezes inesperado em relação às outras capacidades cognitivas do indivíduo e à instrução recebida. Apresentam um perfil cognitivo típico com diminuição da consciência fonológica (capacidade de processar e analisar os sons da linguagem oral), diminuição da memória verbal de curto prazo e de trabalho, dificuldades na nomeação rápida (evocação de vocabulário) a dificuldade na repetição de pseudo palavras. Os indivíduos com dis- lexia têm sérias dificuldades no processo de descodificação, o que os leva a ter uma leitura imprecisa, cometendo erros variados que vão desde trocas de letras até erros por adivinhação. Possuem também fluência e velocidade leitoras diminuídas, com prejuízo da compreensão, pois o processo de descodificação já ocupa grande parte da memória de trabalho. Cometem erros ortográficos frequentes, com confusões fonológicas e que não são plausíveis foneticamente. ${ }^{3-5}$

A Perturbação Cognitiva Não-Verbal surge recentemente como um conceito de perfil cognitivo em que são sobretudo as capacidades não-verbais que estão afectadas. Caracteriza-se por défices da percepção visual (visuo-espaciais; coordenação olho-mão), défices da motricidade, discalculia, disgrafia, desatenção, défices da percepção táctil, bom desempenho linguístico (prosódia - tom e melodia do discurso - peculiar e pragmática - adequação da linguagem aos contextos e interlocutores - pobre) e alterações nas trocas sociais. É um perfil funcional muito típico dos indivíduos com Síndrome de Asperger. ${ }^{3}$

A Perturbação de Hiperactividade e Défice de Atenção (PHDA) é uma perturbação neurobiológica frequente do desenvolvimento e comportamento na infância e na adolescência e é caracterizada por dificuldade em manter a atenção, hiperactividade e impulsividade inapropriadas ao nível de desenvolvimento e idade do indivíduo. O diagnóstico é clínico e deve ser feito recorrendo aos critérios do DSM IV. Estes indivíduos apresentam sérias dificuldades em manter a atenção, em concentrar-se por períodos prolongados, em se organizar, em persistir nas tarefas e possuem uma distractibilidade fácil e exagerada. A desatenção prejudica o seu funcionamento, nomeadamente a aprendizagem académica. A maioria apresenta também excesso de actividade motora: correm, trepam, não são capazes de estar sentados nas aulas, à mesa, no cinema, mexem em tudo e são dificilmente controláveis. Estes comportamentos tornam o convívio social e escolar difíceis. Apresentam também impulsividade exagerada, com impaciência, reacções e respostas irreflectidas, das quais muitas vezes se arrependem. A impulsividade prejudica o desempenho escolar e também afecta o relacionamento social. Têm uma empatia adequada mas o relacionamento social é prejudicado pela dificuldade em acatar as regras do grupo, em cumprir regras de 
jogos que incluem esperar pela sua vez, em inibir comportamentos e respostas desadequadas para o bom relacionamento inter-pares. Possuem baixa capacidade de resistência à frustração, necessidade de novidade e variedade de estímulos constante para manter o interesse pelas actividades e aborrecem-se com facilidade. Apresentam também dificuldades ao nível das funções executivas. Convém enfatizar que, apesar da hiperactividade ser a face visível e mais notada desta perturbação, o défice principal está na desatenção ou seja, na incapacidade em atender de forma continuada aos estímulos relevantes e dificuldade em filtrar e eliminar os estímulos irrelevantes às tarefas em curso. Alguns indivíduos apenas apresentam défice de atenção, sem hiperactividade, sendo este subtipo de PHDA mais frequente no sexo feminino. Podem passar despercebidos e ser diagnosticados mais tardiamente. Alguns sintomas remitem com o crescimento. A hiperactividade tende a diminuir a partir da adolescência, no entanto a desatenção e a impulsividade persistem muitas vezes até à idade adulta. ${ }^{3,5}$

A PHDA coexiste frequentemente com as Perturbações Específicas da Aprendizagem, com a Perturbação de Oposição e com outras perturbações do desenvolvimento. É uma perturbação que, se não for tratada, acarreta risco de insucesso escolar, comportamentos de risco (consumo de drogas ilícitas, alcoolismo e gravidez na adolescência), insucesso laboral e alterações no relacionamento social e familiar.

As Perturbações de Oposição e de Conduta são perturbações disruptivas do comportamento (e coexistem com alguma frequência com a PHDA). As primeiras, caracterizam-se por comportamento opositor e teimosia extremas com desobediência e quebra de regras frequente. As Perturbações de Conduta têm estas características mais marcadas e os indivíduos apresentam comportamentos anti-sociais com violações graves de regras. A Perturbação da Conduta pode evoluir para a perturbação anti-social da personalidade ou perturbação de abuso de substâncias, se não for efectuada uma intervenção atempada. ${ }^{3}$

\section{AGRADECIMENTOS}

Agradeço ao Dr. Miguel Palha pela colaboração neste artigo. Alguns dos conhecimentos aqui transmitidos resultam da reflexão conjunta de uma equipa de pediatras de desenvolvimento do Centro de Desenvolvimento Diferenças/APPT21 liderada por ele.

\section{REFERÊNCIAS BIBLIOGRÁFICAS}

1. Jones S, Martin R, Pilbeam D., editors. The Cambridge Encyclopedia of Human Evolution. Cambridge: Cambridge University Press; 1992.

2. Karmiloff-Smith A. Atypical epigenesis. Developmental Science 2007; 10 (1): 84-8.

3. Gillberg $C$, Harrington R, Steinhausen HC, editors. A Clinician's Handbook of Child and Adolescent Psychiatry. Cambridge: Cambridge University Press; 2006.

4. Snowling MJ, Stackhouse J, editors.A Practitioner's Handbook of Dyslexia Speech and Language.2nd ed. London: Whurr Publishers; 2006.

5. Snowling MJ, Hulme C, editors. Science of Reading: a Handbook. Malden, MA: Blackwell Publishing; 2005.

A autora declarou não possuir conflitos de interesses

\section{ENDEREÇO PARA CORRESPONDÊNCIA}

Paula Pires de Matos

Avenida Fontes Pereira de Melo, $n^{\circ} 3-10 .^{\circ}$ Dto.

1050-115 Lisboa

E-mail: paulapiresdematos@sapo.pt

\section{ABSTRACT}

\section{CHILDHOOD DEVELOPMENTAL DISORDERS - GENERAL CONCEPTS}

Humans have a specific neurodevelopment that correlates with brain development during its evolution as a species. This article will review the developmental risk factors, both genetic and environmental, and their relationship as modulating factors for the final phenotypic expression. The concept of normal quantitative and qualitative development will be defined, as well as the developmental sequences within each of its areas. The key concepts of each developmental disability will be summarised.

Keywords: Developmental Disorders; Risk Factors; Diagnostic Criteria. 